\title{
Soluções nutritivas para produção de porta-enxertos de seringueira
}

\author{
Fabio Olivieri de Nobile ${ }^{1}$, Gabriel Fernando Paro ${ }^{1}$, Rogério Farinelli ${ }^{1}$ \\ ${ }^{1}$ Centro Universitário da Fundação Educacional de Barretos, Av. Professor Roberto Frade Monte n 389, CEP 14783-226, Barretos, SP, Brasil
}

"Autor correspondente:

fonobile@feb.br

Termos para indexação:

Crescimento

Hevea brasiliensis

Nutrição mineral

Index terms:

Growth

Hevea brasiliensis

Mineral nutrition

Histórico do artigo:

Recebido em 08/09/2016

Aprovado em 27/03/2017

Publicado em 31/03/2017

doi: 10.4336/2017.pfb.37.89.1347

\begin{abstract}
Resumo - O objetivo deste trabalho foi avaliar a produção suspensa de porta-enxertos de seringueira com substrato em fertirrigação. Foram testados quatro tipos de soluções nutritivas em delineamento experimental inteiramente casualizado, com 5 repetições. A fertirrigação foi realizada a cada dois dias, utilizando-se $200 \mathrm{~mL}$ da solução por recipiente. Avaliou-se altura de planta, diâmetro de caule $(5 \mathrm{~cm}$ acima do colo da planta), área foliar, número de par de folhas, matéria seca da parte aérea e raízes, teor foliar de nutrientes e porcentagem de plantas aptas à enxertia. Os maiores valores para altura de plantas, número de pares de folhas, diâmetro de caule e área foliar dos porta-enxertos foram obtidos com a concentração mais elevada de nutrientes. $\mathrm{O}$ teor foliar de nutrientes e a porcentagem de plantas aptas à enxertia foram considerados adequados com o uso da fertirrigação na maior dose testada (para $5 \mathrm{~L}: \mathrm{Ca}\left(\mathrm{NO}_{3}\right) 2,5 \mathrm{~g}$, $\mathrm{MgSO}_{4} 1,75 \mathrm{~g} ; \mathrm{KNO}_{3} 1,5 \mathrm{~g} ;\left(\mathrm{NH}_{4}\right)\left(\mathrm{NO}_{3}\right) 1,0 \mathrm{~g} ; \mathrm{NH}_{4} \mathrm{H}_{2} \mathrm{PO}_{4}$ 0,9g; $\mathrm{Zn}\left(\mathrm{NO}_{3}\right)_{2} 0,30 \mathrm{~g} ; \mathrm{CuSO}_{4}$ 0,20g; $\left.\operatorname{EDTA}\left(\mathrm{Fe}^{+2}\right) 0,15 \mathrm{~g}\right)$.
\end{abstract}

\section{Nutrient solutions for rubber-tree rootstocks production}

\begin{abstract}
This work aimed to evaluate the suspended production of rubber-tree rootstocks with substrate in fertirrigation. Treatments were four types of nutritional solutions in completely randomized experimental design, with 5 repetitions. Fertigation was held every two days, using $200 \mathrm{~mL}$ of the solution by container. We evaluated plant height, stem diameter ( $5 \mathrm{~cm}$ above the plant collect), leaf area, number of leaves, dry mass of shoot and of roots, foliar nutrient contents and percentage of plants ready for grafting. The highest values for plant height, number of pairs of leaves, stem, and leaf area of rootstocks were obtained with the highest concentration of nutrients. Foliar nutrient content and percentage of plants ready for grafting were considered adequate by using the maximum fertirrigation dose tested (for $5 \mathrm{~L}: \mathrm{Ca}\left(\mathrm{NO}_{3}\right) 2.5 \mathrm{~g}, \mathrm{MgSO}_{4}$ $1.75 \mathrm{~g} ; \mathrm{KNO}_{3} 1.5 \mathrm{~g} ;\left(\mathrm{NH}_{4}\right)\left(\mathrm{NO}_{3}\right) 1.0 \mathrm{~g} ; \mathrm{NH}_{4} \mathrm{H}_{2} \mathrm{PO}_{4} 0.9 \mathrm{~g} ; \mathrm{Zn}\left(\mathrm{NO}_{3}\right)_{2} 0.30 \mathrm{~g} ; \mathrm{CuSO}_{4} 0.20 \mathrm{~g}$; $\left.\operatorname{EDTA}\left(\mathrm{Fe}^{+2}\right) 0.15 \mathrm{~g}\right)$.
\end{abstract}

\section{Introdução}

O sistema de produção de mudas de seringueira passou por uma grande mudança com o advento da produção em bancadas suspensas, conforme preconizado pela Instrução Normativa (IN) no 29, de 05 de agosto de 2009, do Ministério da Agricultura, Pecuária e Abastecimento
(Brasil, 2009) e pela Resolução no 154 de 22 de novembro de 2013 da Secretaria de Agricultura e Abastecimento do Estado de São Paulo (SAA/SP) (São Paulo, 2013). A normatização e fiscalização deste novo sistema de produção possibilitam melhor qualidade fitossanitária e genética das mudas, alicerce fundamental no processo de expansão da heveicultura, com garantia de produtividade. 
Entretanto, no novo sistema de produção não existem informações quanto à adubação por fertirrigação e substratos em porta-enxertos clonais de seringueira (Guiducci, 2014).

A técnica de fertirrigação é muito usada na produção de mudas, pois garante um melhor desenvolvimento das plantas, conforme observado por Zambrosi et al. (2012) na produção de porta-enxertos de citros. No entanto, para a produção de porta-enxertos de seringueira em viveiro suspenso, são desconhecidas informações científicas sobre as concentrações ideais do formulado N, P e K, de aplicação prática e simples em solução nutritiva, que proporcione um crescimento satisfatório das plantas (Barreto et al., 2016).

No método convencional de produção de mudas de seringueira, onde a semeadura é realizada em canteiros de germinação (sementeira) e em seguida usada repicagem para o plantio em campo, tem-se utilizado fertilizantes que promovam a rápida absorção dos nutrientes, mas que não são adequados para substratos sujeitos à irrigação diária. Uma alternativa promissora e com aceitação crescente entre viveiristas consiste na aplicação de fertilizantes via fertirrigação, pois, aumenta a eficiência de seu uso (as perdas por evaporação superficial são reduzidas), reduzindo a demanda por mão de obra e o custo com máquinas, além de flexibilizar a época de aplicação, podendo as doses recomendadas serem fracionadas, conforme a necessidade da cultura (Zamuner Filho, 2012).

Soluções nutritivas vêm sendo amplamente usadas em estudos de fisiologia vegetal, especialmente nos relacionados aos mecanismos que coordenam o crescimento das plantas. Diversas soluções nutritivas já foram propostas em pesquisas de nutrição mineral de plantas, havendo, em alguns casos, diferenças marcantes entre elas, no que se refere aos macronutrientes (Chen et al., 2011). Para que uma planta se desenvolva e expresse todo o seu potencial produtivo, é necessário um correto suprimento de nutrientes através de formulações existentes. A modificação da solução original de Hoagland, a mais usada na investigação de problemas nutricionais de plantas, configura-se como a base para formulação de várias soluções nutritivas comerciais (Corcioli et al., 2016).

Segundo Martins et al. (2013), a adubação de mudas de seringueira em bancadas e substrato deve ser feita a partir do início da formação, preferencialmente por fertirrigação, e realizada a cada dois ou três dias, em pequenas doses por muda, utilizando macro e micronutrientes. Antes do enchimento do recipiente, também podem ser incorporados ao substrato fertilizantes de liberação lenta à base de fósforo.

O objetivo deste trabalho foi avaliar fontes de soluções nutritivas, aplicadas via fertirrigação, nos teores de macro e micronutrientes no substrato e no crescimento de porta- enxertos de seringueira produzidos em sistema de viveiro suspenso.

\section{Material e métodos}

O experimento foi conduzido no Centro Universitário da Fundação Educacional de Barretos, em Barretos, SP, localizado nas coordenadas geográficas $20^{\circ} 34^{\prime} 25.62$ 'S e 48³3'37.44'W, a $562 \mathrm{~m}$ de altitude. A instalação e condução do experimento foi realizada em ambiente protegido no teto por filme transparente de polietileno de baixa densidade com 0,10 $\mathrm{mm}$ de espessura, e nas laterais por telas antiafídica de abertura de malha $<1 \mathrm{~mm}$.

Para a produção de mudas de seringueira, utilizou-se o porta-enxerto da variedade Tji16, cujas sementes foram coletadas em seringal adulto comercial em bom estado fitossanitário com 50 anos de idade, na Fazenda Santa Helena, localizada na Rodovia Antônio Bruno Km 146 no município de Colina, SP.

A semeadura direta em recipiente em bancada suspensa e ambiente protegido foi realizada no dia 28/02/2014. Adotou-se o procedimento de semeadura de 3 sementes por tubete, proposto por Pereira (1986). Os tubetes apresentavam dimensões de $20 \mathrm{~cm}$ de altura e $6 \mathrm{~cm}$ de diâmetro com capacidade para $288 \mathrm{~cm}^{3}$. O substrato usado foi à base de casca de pínus, fibra de coco de textura grossa e cobertura com serragem grossa, apresentando as seguintes características: $\mathrm{pH}\left(\mathrm{CaCl}_{2} 0,01\right.$ $\mathrm{M})=5,1 ; \mathrm{N}=2 \mathrm{~g} \mathrm{~kg}^{-1} ; \mathrm{P}=0,9 \mathrm{~g} \mathrm{~kg}^{-1} ; \mathrm{K}=2,6 \mathrm{~g} \mathrm{~kg}^{-1}$; $\mathrm{S}=1,7 \mathrm{~g} \mathrm{~kg}^{-1} ; \mathrm{Ca}=5,4 \mathrm{~g} \mathrm{~kg}^{-1} ; \mathrm{Mg}=11,1 \mathrm{~g} \mathrm{~kg}^{-1} ; \mathrm{Fe}$ $=8,2 \mathrm{~g} \mathrm{~kg}^{-1} ; \mathrm{B}=15,2 \mathrm{mg} \mathrm{kg}^{-1} ; \mathrm{Cu}=19,4 \mathrm{mg} \mathrm{kg}^{-1} ; \mathrm{Mn}$ $=126 \mathrm{mg} \mathrm{kg}^{-1} \mathrm{e} \mathrm{Zn}=30,2 \mathrm{mg} \mathrm{kg}^{-1}$.

Foi utilizado o delineamento experimental inteiramente casualizado, com 5 tratamentos, 5 repetições e 25 plantas por parcela.

A irrigação foi realizada com frequência diária com auxílio de mangueira com terminal em chuveiro. Aos 20 dias após à germinação procedeu-se o desbaste das plântulas, no momento em que estas apresentavam raízes e caule em início de desenvolvimento na forma "palito" (com $5 \mathrm{~cm}$ de altura e sem folhas), conforme proposto 
por Benesi (1999). Transcorridos 30 dias após o desbaste, as plântulas foram transplantadas dos tubetes para sacos plásticos pretos perfurados, com dimensões $17 \mathrm{~cm} \mathrm{x}$ $33 \mathrm{~cm}$ e preenchidos com o mesmo substrato comercial utilizado para a germinação, a uma profundidade de $2,0 \mathrm{~cm}$. Os sacos plásticos foram dispostos em fileira dupla em bancadas suspensas a $40 \mathrm{~cm}$ do solo com espaçamento de $45 \mathrm{~cm}$ entre fileiras.

As concentrações das soluções nutritivas para a produção dos porta-enxertos de seringueira foram baseadas na recomendação proposta por Martins et al (2013), sendo preparadas com reagentes inorgânicos (p.a), por serem de pureza próximo a $100 \%$ e alta solubilidade em água destilada. A dissolução desses nutrientes obedeceu a sequência proposta por Furlani et al. (1999), conforme apresentado na Tabela 1.

Tabela 1. Concentração de nutrientes e quantidades de fertilizantes para o preparo de soluções nutritivas para cultivo de porta-enxertos de seringueira.

\begin{tabular}{|c|c|c|c|c|c|}
\hline \multirow{2}{*}{ Nutrientes } & Trat.1 & Trat. 2 & Trat. .3 & Trat. 4 & Trat.5. \\
\hline & \multicolumn{5}{|c|}{ Dose, em g $1.000 \mathrm{~L}^{-1}$} \\
\hline $\mathrm{CaNO}_{3}$ & 500 & 460 & 400 & 300 & ------- \\
\hline $\mathrm{MgSO}_{4}$ & 350 & 300 & 240 & 220 & ------ \\
\hline $\mathrm{KNO}_{3}$ & 300 & 260 & 180 & 60 & ------ \\
\hline $\mathrm{NH}_{4} \mathrm{NO}_{3}$ & 200 & 180 & 160 & 120 & ------- \\
\hline $\mathrm{NH}_{4} \mathrm{H}_{2} \mathrm{PO}_{4}$ & 180 & 100 & 80 & 60 & ------- \\
\hline $\mathrm{Zn}\left(\mathrm{NO}_{3}\right)_{2}$ & 60 & 40 & 30 & 20 & ------ \\
\hline $\operatorname{EDTA}\left(\mathrm{Fe}^{+2}\right)$ & 30 & 20 & 16 & 10 & ------- \\
\hline $\mathrm{CuSO}_{4}$ & 40 & 30 & 24 & 16 & ------ \\
\hline $\mathrm{MnSO}_{4}$ & 40 & 30 & 24 & 20 & ------- \\
\hline $\mathrm{H}_{3} \mathrm{BO}_{3}$ & 30 & 20 & 16 & 10 & ------- \\
\hline $\mathrm{H}_{2} \mathrm{MoO}_{4} \cdot \mathrm{H}_{2} \mathrm{O}$ & 20 & 15 & 10 & 8 & ------- \\
\hline $\begin{array}{l}\text { Condutividade } \\
\text { elétrica }\left(\mathrm{dS} \mathrm{m}^{-1}\right)\end{array}$ & 2,1 & 1,8 & 1,5 & 1,2 & 0,7 \\
\hline
\end{tabular}

Tanto a aplicação da água quanto a aplicação da solução nutritiva foram realizadas através do mesmo sistema de irrigação suplementar. A aplicação das soluções nutritivas teve início aos 30 dias após o transplantio para a sacola plástica. Com auxílio de um becker graduado, adicionou-se $200 \mathrm{~mL}$ de solução nutritiva para cada sacola plástica, de acordo com seus respectivos tratamentos, a cada 2 dias. O restante da irrigação foi feita com base na evapotranspiração, medida através de um atmômetro instalado dentro do ambiente protegido. $\mathrm{O}$ tratamento 5 recebeu apenas água nos dias da fertirrigação.

Após 120 dias do transplantio das mudas dos tubetes para os sacos plásticos, foi feita a diagnose foliar, onde foram retiradas 5 folhas de todas as plantas por tratamento, com 5 repetições, nos quatro pontos cardeais, de ramos sombreados do terço médio da copa, de acordo com a metodologia de Malavolta et al. (1997).

As folhas coletadas foram acondicionadas em sacos de papel identificados, e levadas ao laboratório, sendo posteriormente lavadas e secas em estufa de circulação forçada de ar a $60{ }^{\circ} \mathrm{C} \pm 5{ }^{\circ} \mathrm{C}$ durante $72 \mathrm{~h}$. As folhas secas de cada tratamento foram moídas em moinho tipo Willey com malha de $20 \mathrm{mh}$. Após a moagem, os teores dos macronutrientes: $\mathrm{N}, \mathrm{P}, \mathrm{K}, \mathrm{Ca}, \mathrm{Mg}$ e $\mathrm{S}$ e micronutrientes: $\mathrm{B}, \mathrm{Cu}, \mathrm{Fe}, \mathrm{Mn}$ e $\mathrm{Zn}$ foram determinados quimicamente, conforme metodologia descrita por Malavolta et al. (1997).

Ao final da condução do experimento, as variáveis mensuradas foram: comprimento radicular: com auxílio de uma régua mediu-se a distância do colo da planta até o término da raiz pivotante $(\mathrm{cm})$; massa seca de folhas: as folhas foram coletadas e pesadas em balança de precisão e secas em estufa $\left(60{ }^{\circ} \mathrm{C}\right.$ a $\left.70{ }^{\circ} \mathrm{C}\right)$, com circulação de ar forçada, por $72 \mathrm{~h}$, para obtenção da matéria seca da parte aérea (g.planta ${ }^{-1}$ ); massa seca do sistema radicular: os sistemas radiculares foram separados e pesados em balança de precisão. Após a pré secagem, foram secos em estufa a $60{ }^{\circ} \mathrm{C}-70^{\circ} \mathrm{C}$ com circulação de ar forçada por $72 \mathrm{~h}$, para obtenção da matéria seca do sistema radicular; plantas aptas à enxertia: porcentagem de plantas com diâmetro de caule maior que $1 \mathrm{~cm}$ na região localizada a $5 \mathrm{~cm}$ acima do coleto da planta, conforme os padrões estabelecidos para comercialização de sementes e mudas de seringueira (Brasil, 2009).

Após 30 dias do transplantio das mudas, foram analisados mensalmente os efeitos dos tratamentos sobre o crescimento dos porta-enxertos de seringueira.

A comparação entre os atributos avaliados foi feita por variância (ANOVA), com a aplicação do teste de médias de Tukey (1\% e 5\% de significância). 


\section{Resultados e discussão}

As soluções nutritivas apresentaram diferenças significativas $(\mathrm{p}<0,01)$ para os teores dos macronutrientes $\mathrm{N}, \mathrm{P}, \mathrm{K}$ e Ca em folhas de porta-enxertos de seringueira (Tabela 2). As plantas do tratamento sem fertirrigação (T5) apresentaram clorose nas folhas e hastes, indicando deficiência nutricional. Os sintomas indicavam deficiência de $\mathrm{N}$, tendo os baixos teores de $\mathrm{N}$ causado a morte de plantas.

$\mathrm{O}$ tratamento $\mathrm{T} 1$ apresentou os maiores teores de N, P e K nas folhas de porta-enxertos de seringueira, uma vez que a solução daquele tratamento é mais concentrada em nitrato de cálcio e fosfato monoamônio, fontes desses elementos (Tabela 2).

Amaral (1990) observou teores de $\mathrm{N}$ de $34,0 \mathrm{~g} \mathrm{~kg}^{-1}$ de $\mathrm{N}$ nas folhas utilizando solução nutritiva, sendo que valores adequados de $\mathrm{N}$ em folhas de porta enxertos de seringueira situam-se entre 29,0 e $35 \mathrm{~g} \mathrm{~kg}^{-1}$ (Murbach et al., 2013). Segundo Cruz et al. (2011), dentre os nutrientes, o nitrogênio é o mais absorvido pela seringueira, além de ser o principal responsável pelo crescimento da planta e expansão foliar

Tabela 2. Teores de macronutrientes em folhas de porta-enxertos de seringueira aos 10 meses de idade, submetidas à fertirrigação com diferentes concentrações de soluções nutritivas.

\begin{tabular}{ccccccc}
\hline \multirow{2}{*}{ Tratamentos } & \multicolumn{5}{c}{ Teor de macronutrientes em g kg-1 } \\
\cline { 2 - 7 } & Nitrogênio & Fósforo & Potássio & Cálcio & Magnésio & Enxofre \\
\hline 1 & $39,48 \mathrm{a}$ & $2,51 \mathrm{a}$ & $12,27 \mathrm{a}$ & $9,82 \mathrm{a}$ & 3,35 & 1,81 \\
2 & $37,99 \mathrm{~b}$ & $2,40 \mathrm{~b}$ & $10,50 \mathrm{ab}$ & $7,96 \mathrm{a}$ & 3,93 & 1,63 \\
3 & $34,54 \mathrm{c}$ & $2,28 \mathrm{c}$ & $8,95 \mathrm{bc}$ & $5,17 \mathrm{~b}$ & 2,83 & 1,63 \\
4 & $33,68 \mathrm{c}$ & $2,14 \mathrm{~d}$ & $7,36 \mathrm{c}$ & $4,43 \mathrm{~b}$ & 2,92 & 1,47 \\
\hline Teste F & $18,73^{* *}$ & $41,94^{* *}$ & $19,81^{* *}$ & $27,87^{* *}$ & $2,05^{\mathrm{NS}}$ & $1,11^{\mathrm{NS}}$ \\
Média & 36,41 & 2,33 & 9,77 & 6,85 & 3,05 & 1,63 \\
CV $(\%)$ & 3,93 & 2,32 & 10,81 & 15,45 & 11,62 & 17,95 \\
\hline
\end{tabular}

Médias seguidas de letras distintas diferem entre si pelo teste de Tukey a $5 \%$ de probabilidade. ${ }^{* *}$ significativo a $1 \%$ de probabilidade pelo teste F. Plantas não adubadas não foram analisadas, pois estavam desfolhadas.

O fósforo, segundo Santana et al. (1996), constitui o elemento que apresenta respostas mais consistentes na adubação de seringais, principalmente na fase juvenil, quando o nutriente atuaria estimulando o desenvolvimento do sistema radicular. Gonçalves et al. (2010), mencionam que os valores considerados ideais para o cultivo de seringueira no Estado de São Paulo seriam entre 7,5 a 9,0 $\mathrm{g} \mathrm{kg}^{-1}$ de fósforo. Neste caso há necessidade de ajuste da solução nutritiva para o fósforo, pois as plantas jovens absorvem o elemento mais rapidamente, o que permite um rápido e intenso crescimento das raízes em ambientes com níveis adequados do nutriente.

Cantarutti et al. (2007), estudando soluções nutritivas e avaliando os teores de $\mathrm{K}$, conseguiram encontrar teores em folhas de mudas de seringueira que variaram de 4 a 10 $\mathrm{g} \mathrm{kg}^{-1}$. Em geral, o potássio foi o segundo nutriente com o maior teor nas folhas. Essa rápida absorção de potássio é dependente da permeabilidade relativamente alta das membranas das plantas, que provavelmente resulta de ionóforos localizados na membrana, o que torna possível sua difusão facilitada (Hawkesford et al., 2012).
No caso do Ca os tratamentos T1 e T2 apresentaram os maiores teores em folhas de seringueira, mas ambos se diferenciam dos Tratamentos T3 e T4, em que estes, respectivamente, são iguais quanto ao teor de cálcio (Ca) em função das diferentes soluções nutritivas (Tabela 2). As variações no acúmulo de cálcio são consideradas baixas, de acordo com Cantarutti et al. (2007), que sugerem como teor ideal a faixa entre $10 \mathrm{e} 14 \mathrm{~g} \mathrm{~kg}^{-1}$.

Os teores de $\mathrm{Ca}$ obtidos por Alvin \& Machado (2012) e Cantarutti et al. (2007) variaram em torno de $10 \mathrm{mg} \mathrm{kg}^{-1}$ nas folhas de seringueira e de $30 \mathrm{mg} \mathrm{kg}^{-1} \mathrm{na}$ planta toda, aos 100 dias de idade. Mendes et al. (2012) conduziram um experimento em casa de vegetação, com o objetivo de avaliar o acúmulo de cálcio em portaenxertos de seringueira nas idades de 60, 120, 180 e 240 dias e observaram que o acúmulo de cálcio aos 60 dias apresentou pouca variação, sendo que o maior acúmulo deste nutriente nas folhas foi de $5,3 \mathrm{~g} \mathrm{~kg}^{-1}$ aos 240 dias, valor inferior ao obtido no presente trabalho.

Os teores de $\mathrm{Mg}$ e $\mathrm{S}$ nas folhas de porta-enxertos de seringueira não foram alterados pelas diferentes concentrações de nutrientes nas soluções nutritivas, 
mostrando que para a elaboração de uma fórmula nutritiva para mudas de seringueira há necessidade de se elevar os teores de ambos os elementos. Oliveira (2006), avaliando os teores de macro e micronutrientes em portaenxertos de seringueira em diferentes períodos, observou que a variação de $\mathrm{Mg}$ também foi superior a de $\mathrm{P}$, tendo encontrado valores de $\mathrm{Mg}\left(6,75 \mathrm{~g} \mathrm{~kg}^{-1}\right)$ superiores ao do presente trabalho.

De acordo com Cantarutti et al. (2007), os teores de $\mathrm{S}$ em folhas de seringueira variam de $1,8 \mathrm{~g} \mathrm{~kg}^{-1} \mathrm{a}$ $2,6 \mathrm{~g} \mathrm{~kg}^{-1}$. Nesse caso, apenas o Tratamento T1 não estaria em situação de deficiência, apesar de estar muito próximo do limite inferior, indicando necessidade de maior concentração desse elemento nas soluções nutritivas. Zamuner Filho et al. (2012), estudando doses de adubo de liberação lenta em mudas de seringueira em sacos plásticos com substratos, obteve valores de $3,84 \mathrm{~g}$ $\mathrm{kg}^{-1}$ de $\mathrm{S}$, sendo superiores ao presente trabalho.

As soluções nutritivas representaram diferença significativa $(\mathrm{p}<0,01)$ para o teor dos micronutrientes $\mathrm{Fe}$ e $\mathrm{Cu}$; e $(\mathrm{p}<0,05)$ para $\mathrm{Mn}, \mathrm{Zn}$ e B em folhas de porta-enxertos de seringueira (Tabela 3 ). Todos os valores foram crescentes, conforme o aumento dos elementos nas soluções nutritivas, demonstrando que a planta apresenta resposta positiva na absorção desses elementos.

Tabela 3. Teor de micronutrientes em folhas de porta-enxertos de seringueira aos 10 meses de idade, submetidas à fertirrigação com diferentes concentrações de soluções nutritivas.

\begin{tabular}{cccccc}
\hline \multirow{2}{*}{ Tratamentos } & \multicolumn{5}{c}{ Teores de micronutrientes em mg kg-1 } \\
\cline { 2 - 6 } & Ferro & Manganês & Cobre & Zinco & Boro \\
\hline 1 & $218,66 \mathrm{a}$ & $278,56 \mathrm{a}$ & $14,92 \mathrm{a}$ & $147,29 \mathrm{a}$ & $104,78 \mathrm{a}$ \\
2 & $166,95 \mathrm{ab}$ & $251,14 \mathrm{ab}$ & $9,74 \mathrm{~b}$ & $133,08 \mathrm{ab}$ & $101,00 \mathrm{a}$ \\
3 & $143,55 \mathrm{~b}$ & $224,82 \mathrm{ab}$ & $4,96 \mathrm{c}$ & $126,35 \mathrm{ab}$ & $97,45 \mathrm{ab}$ \\
4 & $132,31 \mathrm{~b}$ & $214,33 \mathrm{~b}$ & $3,72 \mathrm{c}$ & $108,10 \mathrm{~b}$ & $67,14 \mathrm{~b}$ \\
\hline Teste de F & $7,4^{* *}$ & $4,99^{*}$ & $96,73^{* *}$ & $4,37^{*}$ & $5,37^{*}$ \\
Média & 165,37 & 239,71 & 8,33 & 128,70 & 92,59 \\
CV (\%) & 19,7 & 2,32 & 13,91 & 13,52 & 17,95 \\
\hline
\end{tabular}

Médias seguidas de letras distintas diferem entre si pelo teste de Tukey a $5 \%$ de probabilidade. ${ }^{* *}$ significativo a $1 \%$ de probabilidade pelo teste F. Plantas não adubadas não foram analisadas, pois estavam desfolhadas.

De acordo com Cantarutti et al. (2007), a faixa considerada ideal para os teores de micronutrientes em folhas de seringueira são: $\mathrm{Fe}=70-90 \mathrm{mg} \mathrm{kg}^{-1} ; \mathrm{Mn}=15$ - $40 \mathrm{mg} \mathrm{kg}{ }^{-1} ; \mathrm{Cu}=10-20 \mathrm{mg} \mathrm{kg}^{-1} ; \mathrm{Zn}=20-30 \mathrm{mg} \mathrm{kg}^{-1}$; e $\mathrm{B}=20-70 \mathrm{mg} \mathrm{kg}^{-1}$.

O ferro e manganês aumentaram seus teores com o desenvolvimento foliar, apresentando maiores teores na folha senescente. De acordo com Mendes et al. (2012), o ferro é o micronutriente mais absorvido, seguido do manganês. No entanto, nas condições da presente pesquisa, o manganês apresentou o maior teor, devido à sua maior disponibilidade na solução e à inibição da absorção do ferro.

Os teores de ferro estão dentro da faixa ideal, com exceção do T1, que ultrapassou a faixa, porém não afetou o desenvolvimento da planta. $\mathrm{O}$ Fe tem um importante papel na ativação de enzimas, atuando como grupo prostético. Participa em reações de oxidorredução em hemoproteínas e proteínas não-hémicas com ligação $\mathrm{Fe}-\mathrm{S}$ e em ferrodoxina, enzimas redutase, nitrogenase e sulfato redutase. Além disso, catalisa a biossíntese da clorofila, uma vez que faz parte de enzimas responsáveis por sua formação (Malavolta, 2006).

O alto teor de Mn encontrado nas folhas, possivelmente, se deve à sua alta disponibilidade na solução nutritiva. Segundo Pegoraro et al. (2006), sob condições ácidas a disponibilidade de Mn é aumentada, devido à maior solubilidade dos compostos que o contêm, favorecendo, assim, a sua absorção.

Para cobre, apenas o T1 se mostrou dentro da faixa de suficiência. Todos os outros tratamentos não forneceram $\mathrm{Cu}$ em quantidades adequadas para a seringueira. Amarante et al. (2010), analisando a composição química de folhas de macieira, admitem que os baixos teores de cobre obtidos podem estar relacionados ao excesso de manganês, devido à uma relação inversa entre o $\mathrm{Cu}$ e o $\mathrm{Mn}$.

Os teores de zinco e boro também se encontram acima da faixa considerada ideal. A alta disponibilidade de $\mathrm{Zn}$ pode causar efeitos de toxidez em plantas não tolerantes 
e os sintomas são diminuição do sistema radicular e do tamanho das folhas e, consequentemente, diminuição na produção de massa seca na planta, sendo que uma das causas para a redução da produção de massa seca é o acúmulo de calose contida no xilema, o que dificulta a ascensão da seiva (Malavolta, 2006).

Apenas o T4 se encontra na faixa ideal de boro, sendo que todos os outros estão acima dessa faixa. As plantas de seringueira se mostraram tolerantes ao alto nível de boro, pois não foram observadas alterações no desenvolvimento das plantas em função desses altos níveis.

Os teores de macronutrientes nas folhas de seringueira apresentaram a seguinte ordem de concentração decrescente: N, K, Ca, Mg, P e S. Segundo Murbach et al. (2013), o nitrogênio é o nutriente mais absorvido pela seringueira, além de ser o principal responsável pelo crescimento do minijardim e expansão foliar, no caso do eucalipto (Silveira et al., 2014). Para os micronutrientes, o B foi aquele com maior concentração, seguido do Mn, $\mathrm{Fe}, \mathrm{Zn}, \mathrm{B}$ e $\mathrm{Cu}$.

Para os parâmetros fisiológicos avaliados, as soluções nutritivas representaram diferença significativa $(\mathrm{p}<$ $0,01)$ para matéria seca da parte aérea e de raízes; e comprimento de raiz em plantas de porta-enxertos de seringueira (Tabela 4).

Tabela 4. Matéria seca da parte aérea (MSA), Matéria seca das raízes (MSR) e Comprimento da raiz (CR), de porta-enxertos de seringueira em função de concentrações de nutrientes.

\begin{tabular}{cccc}
\hline Tratamentos & MSA & MSR & CR \\
& $(\mathbf{g})$ & $\mathbf{( g )}$ & $\mathbf{( c m )}$ \\
\hline 1 & $78,47 \mathrm{a}$ & $120,96 \mathrm{a}$ & $26,98 \mathrm{a}$ \\
2 & $59,51 \mathrm{~b}$ & $71,81 \mathrm{~b}$ & $25,89 \mathrm{ab}$ \\
3 & $51,79 \mathrm{~b}$ & $69,80 \mathrm{~b}$ & $25,02 \mathrm{ab}$ \\
4 & $42,20 \mathrm{~b}$ & $60,60 \mathrm{~b}$ & $24,05 \mathrm{ab}$ \\
5 & - & - & - \\
\hline Teste F & $67,810^{* *}$ & $195,117^{* *}$ & $23,103^{* *}$ \\
Média & 53,31 & 77,01 & 24,54 \\
CV (\%) & 5,94 & 5,78 & 4,98 \\
\hline
\end{tabular}

Médias seguidas de letras distintas diferem entre si pelo teste de Tukey a 5\% de probabilidade. ${ }^{* *}$ significativo a $1 \%$ de probabilidade pelo teste $\mathrm{F}$.

O tratamento 5 não apresentou plantas vivas para análise na época de coleta, pois devido à falta de nutrientes, não conseguiram completar seu ciclo de vida.

Os maiores valores de MSA e MSR ocorreram com a solução nutritiva do T1, em função da maior disponibilidade de nutrientes. Entretanto, o acúmulo de matéria seca pode ser ainda maior. Oliveira (2006) obteve valores superiores ao encontrado no presente trabalho, com valor médio de $104,5 \mathrm{~g}$ de matéria seca da parte aérea.

Zamuner Filho et al. (2012), avaliando doses de fertilizantes de $0,3,6$ e $9 \mathrm{~g} \mathrm{~L}^{-1}$ de substrato, contento a formulação $\mathrm{N}(15 \%), \mathrm{P}_{2} \mathrm{O}_{5}(9 \%), \mathrm{K}_{2} \mathrm{O}(12 \%), \mathrm{Mg}(1 \%)$, $\mathrm{S}(2,3 \%), \mathrm{B}(0,02 \%), \mathrm{Cu}(0,05 \%), \mathrm{Fe}(1 \%), \mathrm{Mn}(0,06 \%)$, Mo $(0,02 \%)$ e $\mathrm{Zn}(0,05 \%)$, obteve maiores valores de matéria seca da parte aérea com a dose de $6 \mathrm{~g} \mathrm{~L}^{-1}$ de fertilizante, equivalendo a $69,52 \mathrm{~g}$ planta $^{-1}$.

As soluções nutritivas representaram diferença significativa $(\mathrm{p}<0,01)$ de porcentagem de plantas de seringueira aptas à enxertia (PAE \%) (Tabela 5).

Tabela 5. Análise de variância para porcentagem de plantas de seringueira aptas à enxertia (PAE \%) aos 10 meses de idade, submetidas a fertirigação com diferentes concentrações de soluções nutritivas.

\begin{tabular}{cc}
\hline Tratamentos & $\begin{array}{c}\text { PAE } \\
(\%)\end{array}$ \\
\hline 1 & $96 \mathrm{a}$ \\
2 & $88 \mathrm{a}$ \\
3 & $20 \mathrm{~b}$ \\
4 & $12 \mathrm{~b}$ \\
Controle & $0 \mathrm{c}$ \\
\hline Teste F & $255,400^{* *}$ \\
Média & 43,2 \\
CV (\%) & 11,2 \\
\hline
\end{tabular}

Médias seguidas de letras distintas diferem entre si pelo teste de Tukey a 5\% de probabilidade. ${ }^{* *}$ significativo a $1 \%$ de probabilidade pelo teste $\mathrm{F}$.

Provavelmente, a grande parte dos porta-enxertos atingiram o diâmetro de caule acima dos patrões mínimos de comercialização devido à alta concentração de $\mathrm{N}$ e $\mathrm{K}$ contida nas soluções dos tratamentos T1 e T2. Esses nutrientes têm inúmeras funções na planta, destacando-se principalmente, a ativação de vários sistemas enzimáticos, muitos deles participantes dos processos de fotossíntese e regulação osmótica, e o aumento da resistência ao acamamento das plantas e às doenças, pois acelera o processo de lignificação das células esclerenquimáticas, aumentando a espessura da parede celular (Malavolta, 2006).

Observa-se que a menor concentração de nutrientes nas soluções nutritivas (T3 e T4) limitou o desenvolvimento dos porta-enxertos, e as plantas não atingiram o diâmetro do caule $(\geq 1 \mathrm{~cm})$ exigido para mudas com 10 meses de idade, de acordo com a Instrução 
Normativa n ${ }^{\circ} 29$ do Ministério da Agricultura, Pecuária e Abastecimento (Brasil, 2009). Portanto, apenas as mudas dos tratamentos $\mathrm{T} 1$ e $\mathrm{T} 2$ poderiam ser comercializadas dentro dos padrões exigidos.

\section{Conclusão}

A nutrição de porta-enxertos de seringueira deve ser feita empregando-se, preferencialmente, a fertirrigação

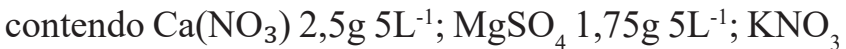
$1,5 \mathrm{~g}_{5 \mathrm{~L}}^{-1} ;\left(\mathrm{NH}_{4}\right)\left(\mathrm{NO}_{3}\right) 1,0 \mathrm{~g} 5 \mathrm{~L}^{-1} ; \mathrm{NH}_{4} \mathrm{H}_{2} \mathrm{PO}_{4} 0,9 \mathrm{~g} 5 \mathrm{~L}^{-1}$; $\mathrm{Zn}\left(\mathrm{NO}_{3}\right)_{2} 0,30 \mathrm{~g}^{-1} ; \mathrm{CuSO}_{4} 0,20 \mathrm{~g} \mathrm{~L}^{-1} ; \operatorname{EDTA}\left(\mathrm{Fe}^{+2}\right)$ $0,15 \mathrm{~g} 5 \mathrm{~L}^{-1}$.

\section{Referências}

Alvim, P. T. \& Machado, A. D. Absorção de minerais e crescimento de cacaueiro e seringueira. In: SEMINÁRIO NACIONAL DA SERINGUEIRA, 1., 2012, Cuiabá. Anais... Cuiabá: Ministério da Indústria e do Comércio, Superintendência da Borracha, 2012. p. 195-203.

Amaral, W. do. Deficiências de macronutrientes e de boro em seringueira (Hevea Brasiliensis). 1990. 44 f. Dissertação (Mestrado em Nutrição Mineral de Plantas) - Escola Superior de Agricultura Luiz de Queiroz, Piracicaba.

Amarante, C. V. T. do et al. Identificação pré-colheita do risco de ocorrência de "bitter pit" em maçãs 'Gala' por meio de infiltração com magnésio e análise dos teores de cálcio e nitrogênio nos frutos. Revista Brasileira de Fruticultura, v. 32, p.27-34, 2010.

Barreto, R. F. et al. Adubação de porta-enxertos de seringueira em viveiro suspenso. Floresta, v. 46, n. 1, p. 1-9, 2016.

Benesi, J. F. C. (Coord.). A cultura da seringueira para o estado de São Paulo. Campinas: SAA/CATI, 1999. 90 p. (CATI. Manual, 72).

Brasil. Ministério da Agricultura e Abastecimento. Instrução Normativa $n^{0} 29$. Dispõe sobre as normas para a produção de sementes e de mudas de seringueira (Hevea spp.). Diário Oficial [da] República Federativa do Brasil, Brasília, DF, n. 149, p. 5-9, 2009.

Cantarutti, R. B. et al. Avaliação da fertilização do solo e recomendação de fertilizantes, p. 769-850. In: Novais, R.F. et al. Fertilidade do solo. Viçosa, MG: Sociedade Brasileira de Ciência do Solo, 2007.

Corcioli, G. et al. Deficiência de macro e micronutrientes em mudas maduras de khaya ivorensis estudadas em viveiro. Cerne, v. 22, n. 1, p. 121-128, 2016. DOI: 10.1590/01047760201622012085.

Chen, B. et al. Development and Implementation of site -specific fertilizer recommendation model based on nutrient balance for rubber plantation. Agronomy Journal, v. 103, p. 464 - 471, 2011.

Cruz, C. A. F. et al. Resposta de mudas de Senna macranthera cultivadas em Argissolo Vermelho-Amarelo a macronutrientes. Ciência Florestal, v. 21, p. 63-76, 2011. DOI: 10.5902/198050982748.
Furlani, P. R. et al. Cultivo hidropônico de plantas. Campinas: Instituto Agronômico de Campinas, 1999. 52 p. (Boletim técnico, 180).

Gonçalves, E. C. P. et al. Fontes de fósforo no crescimento de portaenxerto de seringueira sob condições de viveiro. Floresta, n. 4, v. 40, p. 813-818, 2010. DOI: 10.5380/rf.v40i4.20332.

Guiducci, E. P. Sistemas de produção de porta-enxertos de seringueira. 2014. 48 f. Dissertação (Mestrado em Agronomia) Faculdade de Ciências Agrárias e Veterinárias, Jaboticabal.

Hawkesford, M. et al. Functions of macronutrients. In: Marschner, P. (Ed.). Marschner's mineral nutrition of higher plants. Amsterdam: Elsevier, 2012. p.135-189.

Malavolta, E. et al. Avaliação do estado nutricional das plantas: princípios e aplicações. 2. ed. Piracicaba: Potafos, 1997. 319 p.

Malavolta, E. Manual de nutrição mineral de plantas. Piracicaba: Agronômica Ceres, 2006. 638 p.

Martins, A. L. M. et al. Produção de mudas de seringueira em bancadas e substrato. Campinas: Coordenadoria de Assistência Técnica Integral, 2013. 16 p. (Circular técnica).

Mendes, A. D. R. et al. Concentração e redistribuição de nutrientes minerais nos diferentes estádios foliares de seringueira. Acta Amazônica, n. 4, v. 42, p. 525-532, 2012. DOI: 10.1590/S004459672012000400010.

Murbach, M. R. et al. Nutrient cycling in a RRIM 600 clone rubber plantation. Scientia Agricola, v. 60, n. 2, p. 353-357, 2013.

Oliveira, J. P. de. Crescimento e nutrição mineral de portaenxertos de seringueira (Hevea spp.) em função da idade. 2006. 77 f. Dissertação (Mestrado em Agronomia) - Universidade Federal Rural da Amazônia, Belém.

Pegoraro, R. F. et al. Fluxo difusivo e biodisponibilidade de zinco, cobre, ferro e manganês no solo: influência da calagem, textura do solo e resíduos vegetais. Revista Brasileira de Ciência do Solo, v. 30, p. 859-868, 2006. DOI: 10.1590/S0100-06832006000500012.

Pereira, A. V. Efeito de tipos e tamanhos de sacos plásticos, sobre o desenvolvimento de porta-enxertos de seringueira (Hevea sp.). 1986. 44 f. Dissertação (Mestrado em Agronomia) - Universidade Federal de Lavras, Lavras.

Santana, M. B. M. et al. Fertilidade dos solos ocupados com seringueira no sul da Bahia e grau de tolerância dessa cultura ao alumínio. Revista Theobroma, n. 4, v. 7, p. 125-132, 1996.

São Paulo (Estado). Defesa Agropecuária do Estado de São Paulo. Resolução SAA n ${ }^{\circ}$ 154. Estabelece exigências para cadastramento de viveiros, jardins clonais, plantas matrizes produtoras de sementes e normas técnicas de defesa sanitária vegetal, para a produção, comércio e o transporte de mudas, borbulhas e sementes de seringueira (Hevea spp) no Estado de São Paulo. Diário Oficial do Estado, São Paulo, SP, 2013. Disponível em: <https://www.legisweb. com.br/legislacao/?id=262019 > Acesso em: 20 nov. 2016.

Silveira, E. R. et al. Efeito do espaçamento de plantio na produção de madeira e serapilheira de Eucalyptus dunni na região sudoeste do Paraná. Revista Técnico Científica, v. 1, n. 2, p. 1-9, 2014. 
Zambrosi, F. C. B. et al. Eficiência de absorção e utilização de fósforo em porta-enxertos cítricos. Revista Brasileira de Ciência do Solo, v. 36, n. 2, p. 485-496, 2012. DOI: 10.1590/S010006832012000200018 .
Zamuner Filho, A. N. et al. Doses of controlled-release fertilizer for production of rubber tree rootstocks. Cerne, v. 18, n. 2, p. 239-245, 2012. DOI: 10.1590/S0104-77602012000200008. 